\title{
Water Quality of El Santuario Stream (Tausa-Cundinamarca) from Aquatic Macro Invertebrates and Physicochemical Parameters
}

\author{
Julieth Gallego-Villalobos, Mónica Andrea Castillo-Aguilar* \\ Biology Research Group-GRIB, Faculty of Sciences, Biology Program, Universidad El \\ Bosque. Bogotá, Colombia
}

\begin{abstract}
Article Type: Article
Article Citation: Julieth GallegoVillalobos, Mónica Andrea CastilloAguilar. Water quality of El Santuario stream (Tausa-Cundinamarca) from aquatic macro invertebrates and physicochemical parameters. Indian Journal of Science and Technology. 2020; 13(10), 1116-1123. D0l: 10.17485/ ijst/2020/v013i10/146318
\end{abstract}

Received date: July 7, 2019

Accepted date: November 13, 2019

*Author for correspondence: Mónica Andrea Castillo-Aguilar - monicastilloa@gmail.com 9 Funding source - Vicerrectoría de Investigaciones $\mathrm{PCl}$ - 2015-8774. Biology Research Group-GRIB, Faculty of Sciences, Biology Program, Universidad El Bosque. Bogotá, Colombia

\begin{abstract}
Objectives: To study the water quality of the El Santuario creek located in the El Santuario Reserve, through the macroinvertebrate community analysis and physicochemical parameters. Methods/ statistical analysis: We applied the BMWP/Col-ASPT quality index to characterize surface water quality, collecting aquatic macroinvertebrates in 7 stations of the El Santuario stream, with the measurement of physicochemical parameters between the months of March and August 2017. A constrict correlation analysis (CCA) was conducted to find the relations between macroinvertebrates families and physicochemical variables. Findings: Moderately contaminated waters of dubious quality are defined which may lead to limitations in the establishment of the macroinvertebrate community, where the last station that corresponds to the exit of water of the mine, presented the quality of strongly contaminated waters in a critical situation that is reflected with the low presence of organisms. The physicochemical variables that most influence the families of benthic macroinvertebrates are as follows: conductivity, $\mathrm{pH}$, total dissolved solids, and dissolved oxygen; indicating a relationship between concentration and abundance of organisms. According to the BMWP/Col-ASPT index, the biological quality of the El Santuario creek water has improved significantly in two years without coal mining, in relation to the quality reported for 2015. Application: These results contribute to environmental decision making in the management of high mountain water resources.
\end{abstract}

Keywords: Water Quality, Aquatic Macro Invertebrates, Stream, Physicochemical Parameters, Páramo.

\section{Introduction}

In recent years, the concept of water quality has changed from a purely physicochemical approach to one that integrates the other components of the ecosystem such as biological 
communities [1]. Where the communities of aquatic macroinvertebrates have been used as the reference of the anthropic affectations through the analysis of taxonomic composition and structure of the community to be sensitive to changes of the environment. The importance of the study of water has generated study and management tools for the efficient use of the country's river basins through Colombian National policies [2]. Where an integral evaluation of the resource, allows to obtain information of the biological communities, of the physical-geographical and physicochemical characteristics allowing a follow-up through time. By taking into account the indicator organisms of the environment it is possible to observe the fluctuations of pollution [3].

\section{Methodology}

\subsection{Area of Study}

The El Santuario creek is located in the San Antonio Sanctuary Mines Reserve in the rural area of the municipality of Tausa, Department of Cundinamarca (Figure 1). The creek is located between 3624 and $3720 \mathrm{~m}$ of altitude with an average value of relative humidity in the ranges of $80-90 \%$ and an average temperature of $8{ }^{\circ} \mathrm{C}$.

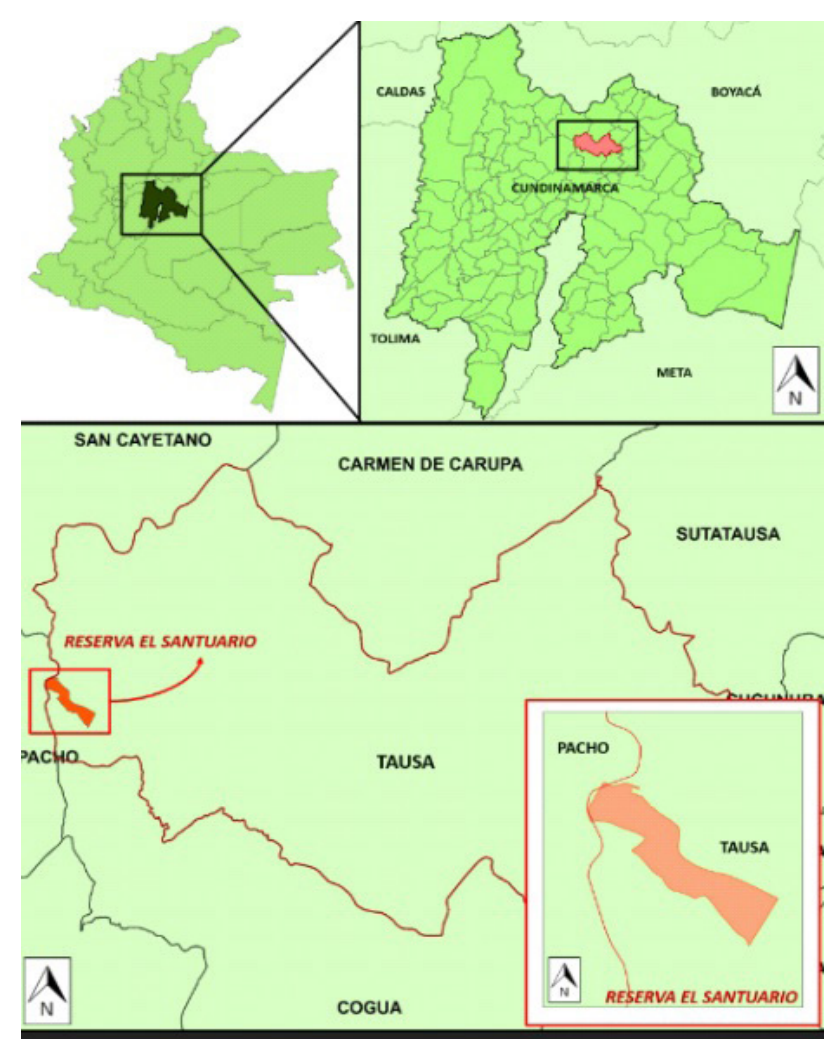

FIGURE 1. Location of El Santuario reserve at the national and municipal levels, prepared by: Julieth Gallego. 
The El Santuario mines reserve is located within the páramo of Guargua, which in turn is part of the páramo complex of Guerrero to the north of Cundinamarca; this complex group 39,240 ha of páramo ecosystems between the municipalities of Carmen de Carupa, Tausa, Zipaquirá, Subachoque, Cogua, Pacho, San Cayetano y Susa [4].

The study was conducted during the months of March to August 2017. Seven sampling zones were established along the creek upstream and one station downstream of the connection point with the coal mine water exit. Monthly samplings were carried out for a total of 35 sediment samples of the water resource under study.

\subsection{Collection of Organisms}

The individuals were collected using a $30 \mathrm{~cm} \times 30 \mathrm{~cm}$ surber net with a $300 \mu$ mesh pore, which was placed in the bed of the downstream against the water current, disturbing the sediment for a time of $2 \mathrm{~min}$, with three repetitions at the point to be sampled [5].

The collected samples were placed in plastic bottles of $500 \mathrm{ml}$ properly labeled, adding alcohol at a concentration of $70 \%$, in order to carry out an adequate preservation during transport. For the cleaning of the samples, a set of sieves of $500 \mu, 180 \mu, 90 \mu$, and $45 \mu$ were implemented, which were placed in a decreasing manner in relation to the size of the microns, placing the sediment sample in the first sieve to wash the sample.

In addition, manual collection was performed by lifting submerged rocks for a period of 20 min per station throughout El Santuario creek. This, in order to find on its surface adhered organisms that were removed using entomological tweezers and brushes. Once the macroinvertebrates were located, they were placed in plastic vials with $70 \%$ alcohol duly labeled. All samples of organisms were transported from the study site to the INBIBO Biology Research Laboratory at Universidad El Bosque, where they were refrigerated at a constant temperature of $4^{\circ} \mathrm{C}$.

\subsection{Physical-Chemical Parameters}

Monthly records were taken at each station of environmental variables of the water body: $\mathrm{pH}$, dissolved oxygen, total dissolved solids, conductivity, temperature, and salinity, using a multiparameter HANNA HI9829. Additionally, water samples were taken in sterile glass containers with a capacity of $500 \mathrm{ml}$ and a screw cap, which were placed directly under the flow of the countercurrent effluent until the necessary volume was completed. The samples were transported from the study site in a portable refrigerator to the INBIBO Biology Research laboratory at Universidad El Bosque, where they were fixed with $\mathrm{H}_{2} \mathrm{SO}_{4}$ at $\mathrm{pH}<2.0$ for proper preservation during the time of analysis, which were cooled at a constant temperature of $4{ }^{\circ} \mathrm{C}$, during the analysis process by means of a COD Reactor and Test Tube Heater HI 839800 and a COD and Multiparameter Bench Photometer HI 83099, to obtain DQO and phosphorus data. Finally, analyses of DBO, nitrites, and nitrates were performed using the protocols established by the ANASCOL S.A.S. Laboratory in Bogotá using Standard Methods for the Examination of Water and Wastewater [6]. 


\subsection{Data Analysis}

The biological material was determined up to the family level, thus evaluating all the benthic fauna of El Santuario creek collected during the sampling season. In order to define correlations between the abundance of aquatic macroinvertebrates, with physicochemical parameters and sampling stations, a constrict correlation analysis (CCA) was performed in the statistical program RStudio.

For the analysis of water quality, the biotic index Biological Monitoring Working Party Index/Average score per taxa BMWP/ASPT modified for Colombia [7] was used. The method defines a score from 1 to 10 according to the tolerance of the different groups to organic contamination [8].

\section{Results}

A total of 989 benthic macroinvertebrate individuals belonging to 9 orders and 15 families were collected, with a total of 12 identified genera. The most abundant families were Hyalellidae with 500 individuals (51\%) of the order Amphipoda and the family Helicopsychidae (28\%) of the order Trichoptera. While the family Simuliidae was the least representative $(0.1 \%)$ belonging to the Diptera order (Figure 2 ).

The CCA (Figure 3) highlights the variables that were most closely related to aquatic macroinvertebrate families where, conductivity, $\mathrm{pH}$, TDS, and dissolved oxygen, which are influencing the families Ceratopogonidae, Chironomidae, and Scirtidae, respectively; where the higher the concentration of these variables in the greater environment may become the abundance of organisms.

In the results of the physical-chemical parameters of the water, the basic parameters were determined with temperature ranges $\left(8-9^{\circ} \mathrm{C}\right), \mathrm{pH}(6.8-7.6)$, dissolved oxygen $(4-5$ $\mathrm{mg} / \mathrm{l})$, total dissolved solids (5-10 ppm), and conductivity (12-24uS) recorded during the six months of the study.

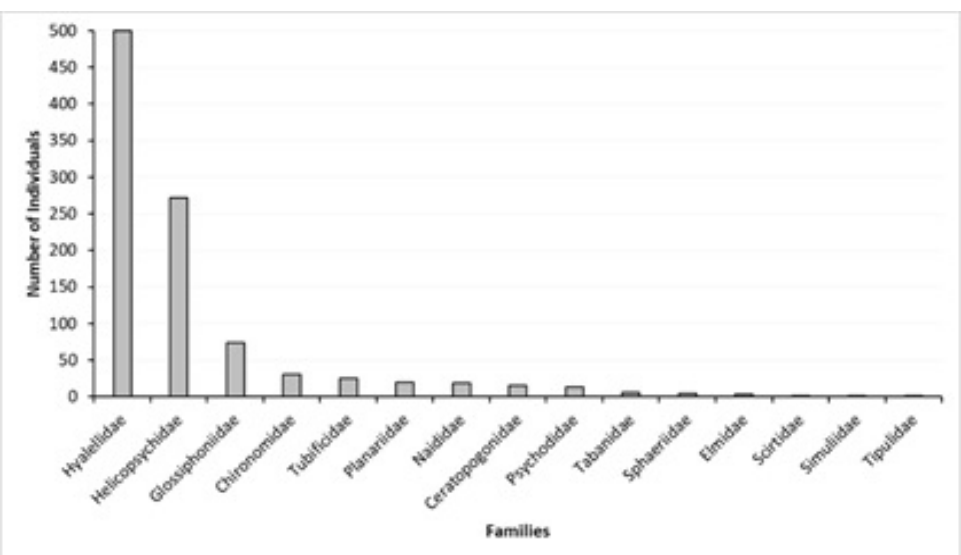

FIGURE 2. Families of aquatic macroinvertebrates found in the El Santuario creek, between March and August 2017. 


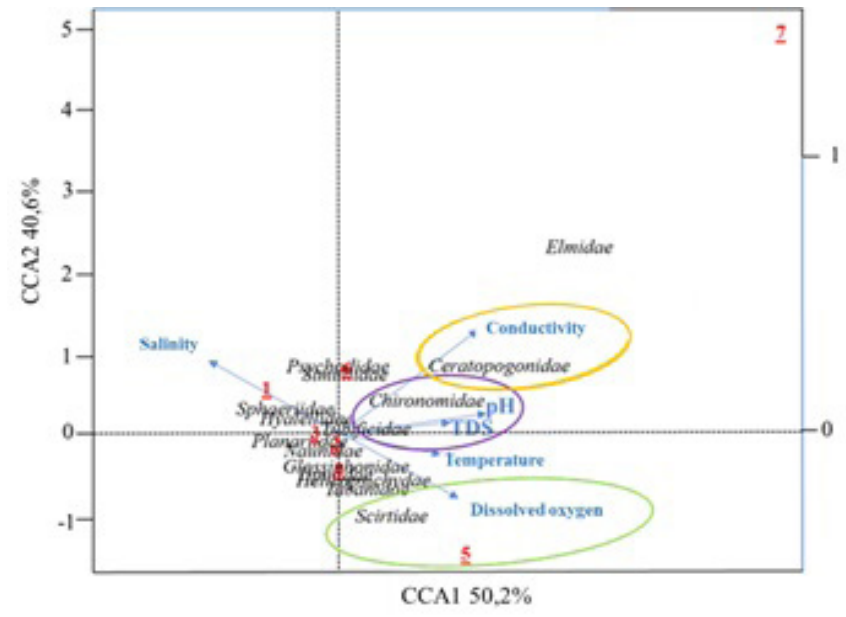

FIGURE 3. CCA of the different environmental variables and families sampled in 7 seasons.

According to the values of the BMWP/Col-ASPT index, El Santuario creek presents mostly class III waters (range $=4.5-6.5$ ) that correspond to water systems with moderately polluted waters of doubtful quality. There is a decrease in the number of families as the quality of the water resource declines, mainly in station seven where the creek receives the contribution of water from the coal mine, reporting the value of the lowest BMWP/ Col-ASPT index catalogued as class V (range $=1-3$ ), becoming heavily polluted water in critical situation (Figure 4).

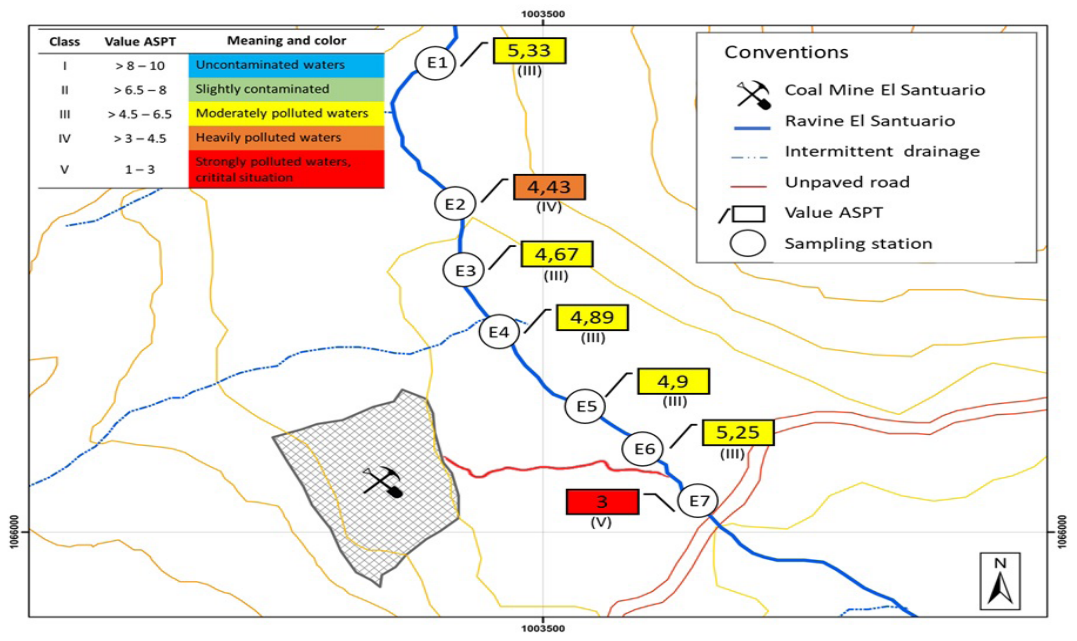

FIGURE 4. Water quality map with BMWP/Col-ASPT index values at the seven sampling stations. 


\section{Discussion}

Macroinvertebrates are organisms that exhibit different levels of tolerance to contamination, mainly by organic matter [9]. The amphipods of the Hyalellidae family are small epigeal crustaceans very common in inland waters, they play an important role in the trophic chains [10] being food for other organisms such as fish and insects allowing the transfer of energy to other higher trophic levels [11]. These crustaceans achieve high densities in systems with high organic matter values by being detrivorous [12], specifically in systems with the low flow that favors the formation of dense populations. On the other hand, the tricopterans of the family Helicopsychidae are considered organisms that live in running, clean, and oxygenated waters [8], being a widely distributed group in the tropics and recognized as intolerant to contamination levels [13]. On the other hand, the diptera of the family simullidae have a preference for waters with high levels of oxygen in rivers and creeks [14-16] and the conditions reported in El Santuario creek are low, possibly absent of high densities of these diptera.

The dynamics of lotic systems are defined by hydrological and climatic behavior. The diptera macro invertebrates of the families Chironomidae and Ceratopogomnidae are predatory organisms where their food preference is coarse organic matter and detritus [17], allows to link them as indicators of high organic load or environments that present some degree of ecological alteration [18]. Likewise, the ranges of dissolved oxygen below $7.6 \mathrm{mg} / \mathrm{l}$ favor the establishment of chironomides, an important group that is reported in this work.

The CCA highlights the relationship between the Ceratopogonidae family with conductivity values, and chironomides with the $\mathrm{pH}$ variable where neutral values tend to be conducive to the family, favoring distribution space-time of the larvae [19].

Aquatic coleoptera have great ecological importance in water bodies, the Scirtidae family defined as crushers-filterers take advantage of decaying plant material [20]. The families Chironomidae and Scirtidae are proposed as possible indicators of the degree of anthropic intervention [21].

The BMWP/Col-ASPT index is proposed as an approximation for evaluating the country's aquatic systems. The results obtained generally indicate class III waters classified as moderately contaminated, which relate to anthropic activities carried out in the study area for 40 years, where coal extraction took place. This type of water may create certain limitations for its establishment to the community of aquatic macroinvertebrates. Compared to the work done in 2015 [22], the biological quality of the surface waters of El Santuario creek has shown an improvement, highlighting that two years ago mining was stopped.

\section{Conclusions}

The macroinvertebrate community reported in the El Santuario creek basin during the study period is not very diverse, where small amphipod crustaceans and trichoptera of the Helicopsychidae family represent $79 \%$ of the abundance of the reported organisms. 
Water Quality of El Santuario Stream (Tausa-Cundinamarca) from Aquatic Macro Invertebrates and Physicochemical Parameters

The BMWP/Col-ASPT index applied for the El Santuario creek corresponds to Class III which represents moderately contaminated water, which has improved in two years without coal mining.

The results of the multivariate analysis of Constrictive Correlation suggest that in some cases the $\mathrm{pH}$, total dissolved solids, conductivity, and dissolved oxygen favor the presence of bioindicating organisms in El Santuario creek, in addition to influencing the stability of the other families sampled.

\section{References}

1. Bioindication of water quality in Colombia: proposal for the use of the BMWP Col method. https://translate.google.com/\#view=home\&op=translate\&sl=auto\&tl=en\&text=Bioindicaci\% C3\%B3n\%20de\%20la\%20calidad\%20del\%20agua\%20en\%20Colombia\%3A\%20propuesta\%20 para\%20el\%20uso\%20del\%20m\%C3\%A9todo\%20BMWP\%20Col. Data accessed: 2003.

2. 2.Decree 1640 de 2012 . https://translate.google.com/\#view=home\&op=translate\&sl=auto\&tl=e n\&text=Decreto\%201640\%20de\%202012. Date accessed: 2012.

3. Aquatic macro invertebrates and river water quality. https://translate.google.com/\#view=ho me\&op=translate \&sl=auto\&tl=en\&text=Macroinvertebrados\%20acu\%C3\%A1ticos\%20y\%20 calidad\%20de\%20las\%20aguas\%20de\%20los\%20r\%C3\%ADos. Date accessed: 1996.

4. Atlas of Paramos of Colombia.pdf. https://translate.google.com/\#view=home\&op=translate\&sl =auto\&tl=en\&text=Atlas\%20de\%20Paramos\%20de\%20Colombia.pdf. Date accessed: 2014 .

5. Protocol for collecting and preparing benthic macroinvertebrate samples in streams. https://translate.google.com/\#view=home $\&$ op $=$ translate $\& \mathrm{sl}=$ auto $\& \mathrm{tl}=\mathrm{en} \& \mathrm{text}=$ Protoc olo\%20de\%20coleta\%20e\%20prepara\%C3\%A7\%C3\%A3o\%20de\%20amostras\%20de\%20 macroinvertebrados\%20bent\%C3\%B4nicos\%20em\%20riachos. Date accessed: 2006.

6. Standard methods for the examination of water and wastewater. https://www.academia. edu/38769108/Standard_Methods_For_the_Examination_of_Water_and_Wastewater_23nd_ edition. Date accessed: 2017.

7. Macroinvertebrates as water quality bioindicators: four decades of development in Colombia and Latin America. http://www.scielo.org.co/pdf/racefn/v40n155/v40n155a07.pdf Date accessed: $17 / 06 / 2019$

8. Fundamentals of neotropical limnology. https://translate.google.com/\#view=home\&op=trans late\&sl=auto\&tl=en\&text=Fundamentos\%20de\%20limnolog\%C3\%ADa\%20neotropical. Date accessed: 2008.

9. Aquatic macroinvertebrates and their importance as bioindicators of water quality in the Alambi River. https://translate.google.com/\#view=home\&op=translate\&sl=auto\&tl=en\&t ext=Macroinvertebrados\%20acu\%C3\%A1ticos\%20y\%20su\%20importancia $\% 20$ como $\% 20$ bioindicadores\%20de\%20calidad\%20del\%20agua\%20en\%20el\%20r\%C3\%ADo\%20Alambi. Date accessed: 2006.

10. Two new species of Hyalella from Southern Brazil (Amphipoda: Hyalellidae) with a taxonomic key. https://academic.oup.com/jcb/article/26/3/355/2670448. Date accessed: 07/2006.

11. Pilgrim W, Burt MD. Effect of acute $\mathrm{pH}$ depression on the survival of the freshwater amphipod Hyalella azteca at variable temperatures: field and laboratory studies. Hydrobiologia. 1993, 254(2), 91-98.

12. Macroinvertebrates of the Ebro Basin: taxon description and identification guide. https:// translate.google.com/\#view=home\&op=translate\&sl=auto\&tl=en\&text=Macroinverteb 
rados\%20de\%20la\%20Cuenca\%20del\%20Ebro\%3A\%0Adescripci\%C3\%B3n\%20de\%20 taxones\%20y\%20gu\%C3\%ADa\%20de\%20identificaci\%C3\%B3n. Date accessed: 10/2009.

13. Determining water quality by means of biological and physicochemical indicators in the fish cultivation station of the Universidad de Caldas, Municipality of Palestina, Colombia. http:// www.scielo.org.co/scielo.php?script=sci_arttext\&pid=S0123-30682009000200007. Date accessed: 12/2009.

14. Ecological effects of waste water: applied limnology and pollutant effects. https://www.amazon. com/Ecological-Effects-Waste-Water-limnology/dp/041234940X. Date accessed: 10/11/1992.

15. Water pollution and distribution of the black fly (Diptera: Simuliidae) in the Atlantic Forest, Brazil. https://www.scielo.sa.cr/scielo.php?pid=S0034-77442015000300683\&script=sci arttext\&tlng=en. Date accessed: 09/2015.

16. Abundance and diversity of black flies (Diptera: Simuliidae) in rivers of the Andean Eastern Hills of Bogotá (Colombia), and its relationship with water stream physicochemical variables. https://doi. org/10.11144/Javeriana.SC23-2.aado; https:/revistas.javeriana.edu.co/index.php/scientarium/ article/view/20385. Date accessed: 2018.

17. Merritt RW, Wallace JB. Aquatic habitats. http://ibimm.org.br/wp-content/uploads/2017/05/ enciclopedia-de-insetos-ingles.pdf. Date accessed: 20/08/2018.

18. Ecological evaluation of the Lliquino river through aquatic macroinvertebrates, PastazaEcuador. http://bibliotecadigital.univalle.edu.co/bitstream/10893/4416/1/Evaluacion\%20 ecologica.pdf. Date accessed: 15/06/2019.

19. Spatial and temporal distribution of larvae of Chironomidae (Diptera) in an Andean stream (Uspallata, Mendoza, Argentina). https://biotaxa.org/RSEA/article/view/30570. Date accessed: 2008.

20. Assemblage of aquatic macroinvertebrates and its relationship with physical and chemical variables in the Wetland Jaboque-Colombia. http://www.scielo.org.co/scielo.php?script=sci abstract\&pid=S0366-52322013000200013. Date accessed: 2013.

21. Macroinvertebrates associated with Guzmania mitis L.B. Sm. (Bromeliaceae) in two fragments of oak grove. http://www.scielo.org.co/scielo.php?script=sci_arttext\&pi $\mathrm{d}=$ S0120-07392013000100001. Date accessed: 06/2013.

22. Biotics, physicochemical characteristics and water quality of the El Santuario Stream, municipality of Tausa. https://translate.google.com/\#view=home\&op=translate\&sl=auto\&tl= en\&text=Biotics\%2C\%20physicochemical\%20characteristics\%20and\%20water\%20quality\%20 of $\% 20$ the $\% 20$ El\%20Santuario\%20Stream\%2C\%20municipality\%20ofTausa. Date accessed: 2015. 